http://dx.doi.org/10.1590/0370-44672014680125

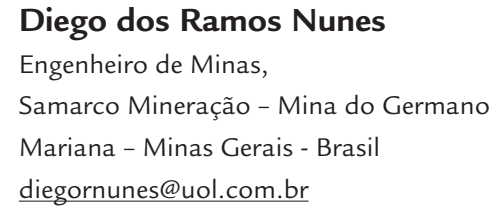

José Margarida Silva

Professor,

Universidade Federal de Ouro Preto -

Escola de Minas - UFOP

Departamento de Engenharia de Minas

Ouro Preto - Minas Gerais - Brasil

jms@demin.ufop.br

\section{Introduction}

Improvement of the operational cost in mining has driven a search for alternative venue for mine waste disposal in some instances. In this area, traditional methods for mine waste dump construction are bench and layer (SCHRODER, 2003). Only in a very few cases, have waste dumps been or are being built using conveyor belt and spreader. In this scenario, use of the conveyor belt and spreader disposal method has been recently considered in Brazilian mines, especially by the iron ore industry.

In Brazil there is no report of operations using this technique. Therefore, it seems wise to understand how this technology works and what are its potential strengths and constraints before implementing this construction option (SAMARCO MINERAÇÃO S.A, 2010).

The proposal of this paper is to report the understanding of this operation

\title{
Waste disposal using a spreader and conveyor belt method
}

\begin{abstract}
In the search for opportunities to decrease operational costs in iron ore mining, waste disposal by conveyor belt has been considered as an alternative. In this work, this form of waste dump is investigated by means of the construction of a test pile and the assessment of geotechnical characteristics such as shear strength and in situ densities. Results were compared with two other dumps built by the traditional methods of bench and layer. The overall conclusion of this research shows that densities are $10 \%$ lower and shear strengths measured by a penetrometer are ten times lower in comparison with the other dumps. Therefore, a good understanding of this method and a thorough discussion of the project parameters are suggested before construction.
\end{abstract}

keywords: Mine waste dump, mine waste disposal, conveyor belt and spreader method.

which was obtained by building a test waste dump with the above mentioned technology. Measurement results in terms of density and resistance were compared with corresponding data collected at others waste dumps constructed using the traditional disposal methods.

Research planning included a review of the main mechanisms involved in these methods, such as mechanic compaction and spreading, the latter also known as pluviation. In the traditional methods, material is discarded in a loose state and compacted to a certain degree of compaction (densification) by the traffic of transport and auxiliary equipment such as trucks and dozers, respectively (BUENO and COSTA, 2012). Regarding the conveyor belt and spreader system, the material is brought to the area by a conveyor belt at a certain flow rate and is thrown in the air and piles up on the terrain (SAMARCO MINERAÇÃO S.A, 2009).

Depending on certain variables such as fall height and flow rate, especially the last one, the waste dump will be in a loose state (high void ratios), and will be very compressible with low resistance (OLIVEIRA FILHO, 1987). These expected results for the conveyor belt and spreader disposal method may look disadvantageous when compared with the traditional methods under the point of view of dump structural strength. Thus, it seems relevant for dump design and dump method selection, to evaluate how resistance, compressibility and permeability will behave in this case, when compared with the waste dumps built with traditional methods. The specific goal of this research is to help to answer the aforementioned questions.

\section{Material and experimental arrangements}

Three test waste dumps were built each one according to a different disposal method: bench, layer, and conveyor belt and spreader. In order to make a comparison, dump performance was evaluated in terms of moisture content, density and resistance. To measure resistance, a penetrometer called Dynamic Cone Penetrometer (DCP) was used. The 
DCP was developed by the Transvaal Road Department of South Africa and its use has spread worldwide for quality control of road pavement construction (RESENDE et al., 2013)

The test consists of dropping an 8-kg cylinder (dead mass) into a rod, set at an upright position, and registering

\subsection{Conveyor belt waste dump}

A crusher system facility was used to simulate waste disposal by conveyor belt and spreader. The crusher was bypassed its penetration into the terrain every time the cylinder strikes the rod. The penetration measurement is reported in $\mathrm{mm}$ per each blow and this is known as DCP index or simply DCP. The plastic and water method was used for in situ density determination. A cubic cave $(0.4 \mathrm{~m}$ side) was dug at the dump surface,

and the screening was sealed, so that the waste physical parameters (particle size) would not be modified. Only conveyor

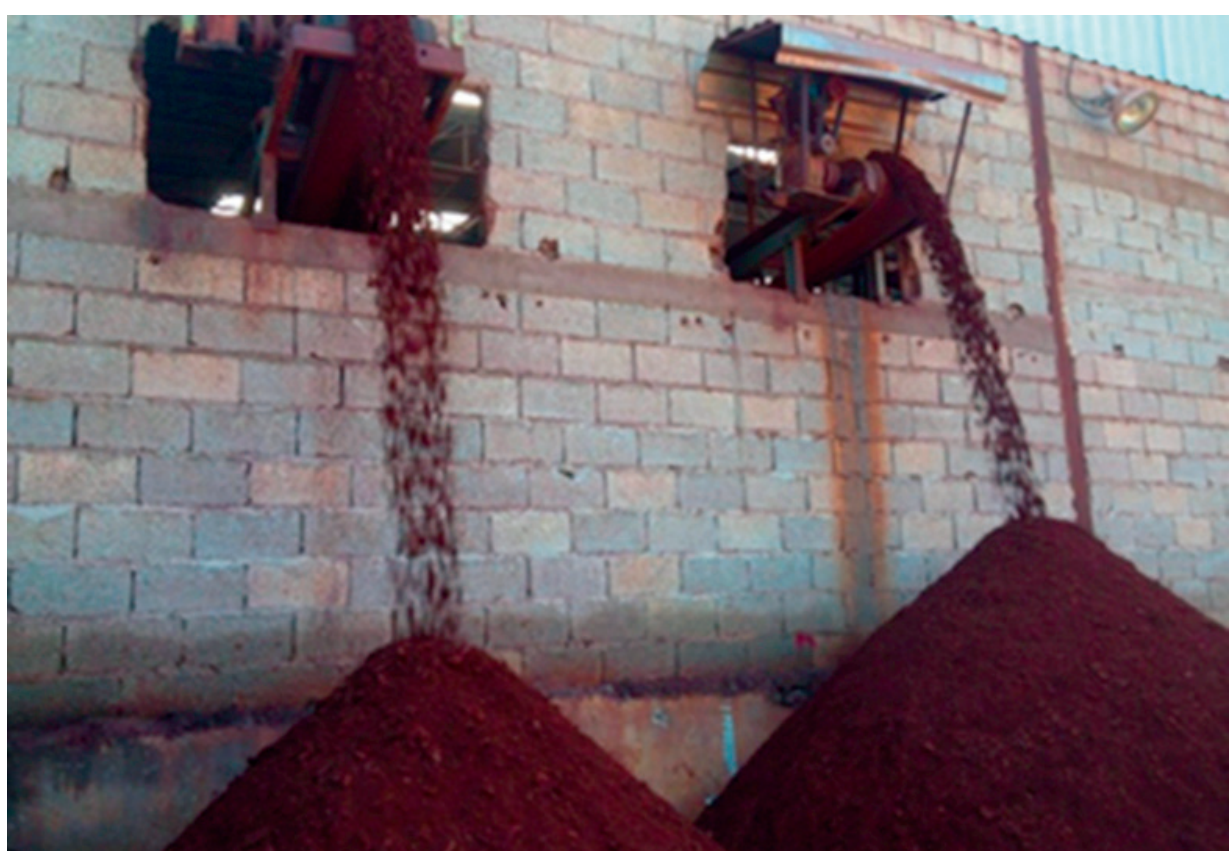

The density and the DCP tests were performed on the top of the waste dumps, after they had been flattened to allow performing these tests. Three different piles

\subsection{Bench waste dump}

This test was done at the João Manoel waste dump (Samarco Mineração S.A.). A 5-m high operational bench was constructed. Trucks dumped material $10 \mathrm{~m}$ away from the border. Thereafter, a dozer pushed the material over the tip. This end dump operation wrapped with a sheet of flexible plastic, and filled with water. Both waste material and water were measured to determine density. From the waste material dug for the density test, samples were also taken for water content and basic geotechnical characterization (grading and specific gravity).

belts were used to produce material pluviation to build the waste dumps, as shown in Figure 1. were constructed, one for each day of tests. As shown in Figure 1, in the first day, the waste dump was built using two conveyor belts to replicate an in-line disposal opera-
Figure 1

Waste dumps in construction by the conveyor belt method.

tion. On the other days, only one waste dump was built, in order to make possible the investigation of density and resistance at different depths.

has a certain similarity with pluviation, producing a loose state structure, but to a lesser extent. The intense traffic of trucks and dozer operations give the bench a certain compaction at least close to the surface.

In order to obtain densities and resistance profiles, a pit was opened to access material behavior at different depths. The tests were performed on the top of small berms, left during the pit excavation. This situation can be seen schematically in Figure 2. Figure 3 also shows a view of the site.

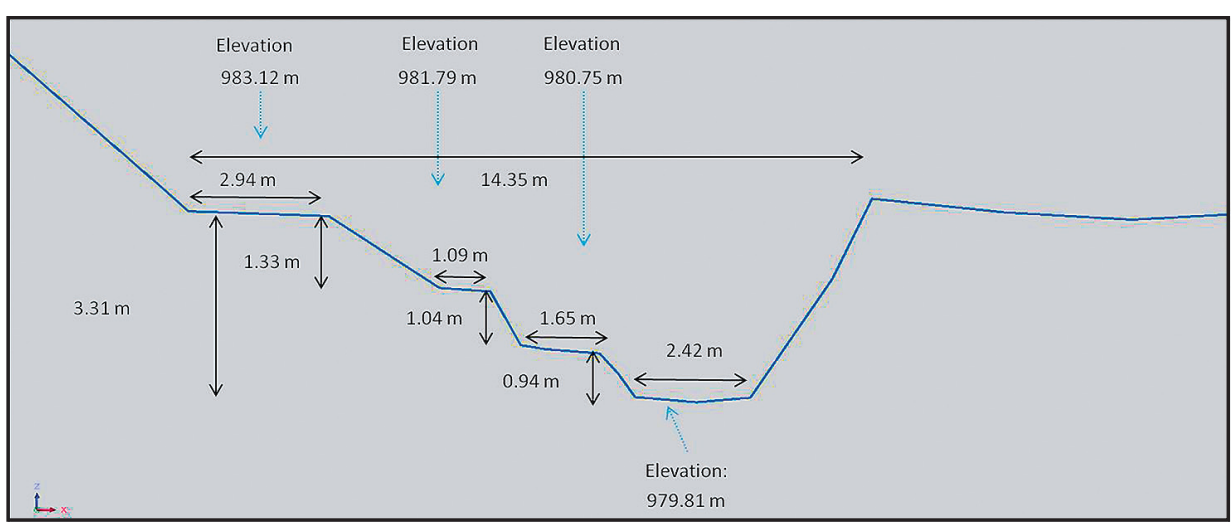

Figure 2

Profile of the pit opened for testing in the bench dump. 
Figure 3

One-meter high berms modeled for testing in the bench dump.

In each berm two densities and 12 DCP tests were performed, which totals 8

\subsection{Layer waste dump}

This testing structure was also built at the Joao Manoel waste dump (Samarco Mineração S.A.). Trucks dumped the waste at an active platform, forming several small heaps. A dozer flattened those heaps, making a layer $1.5-\mathrm{m}$ high layer. On top of the

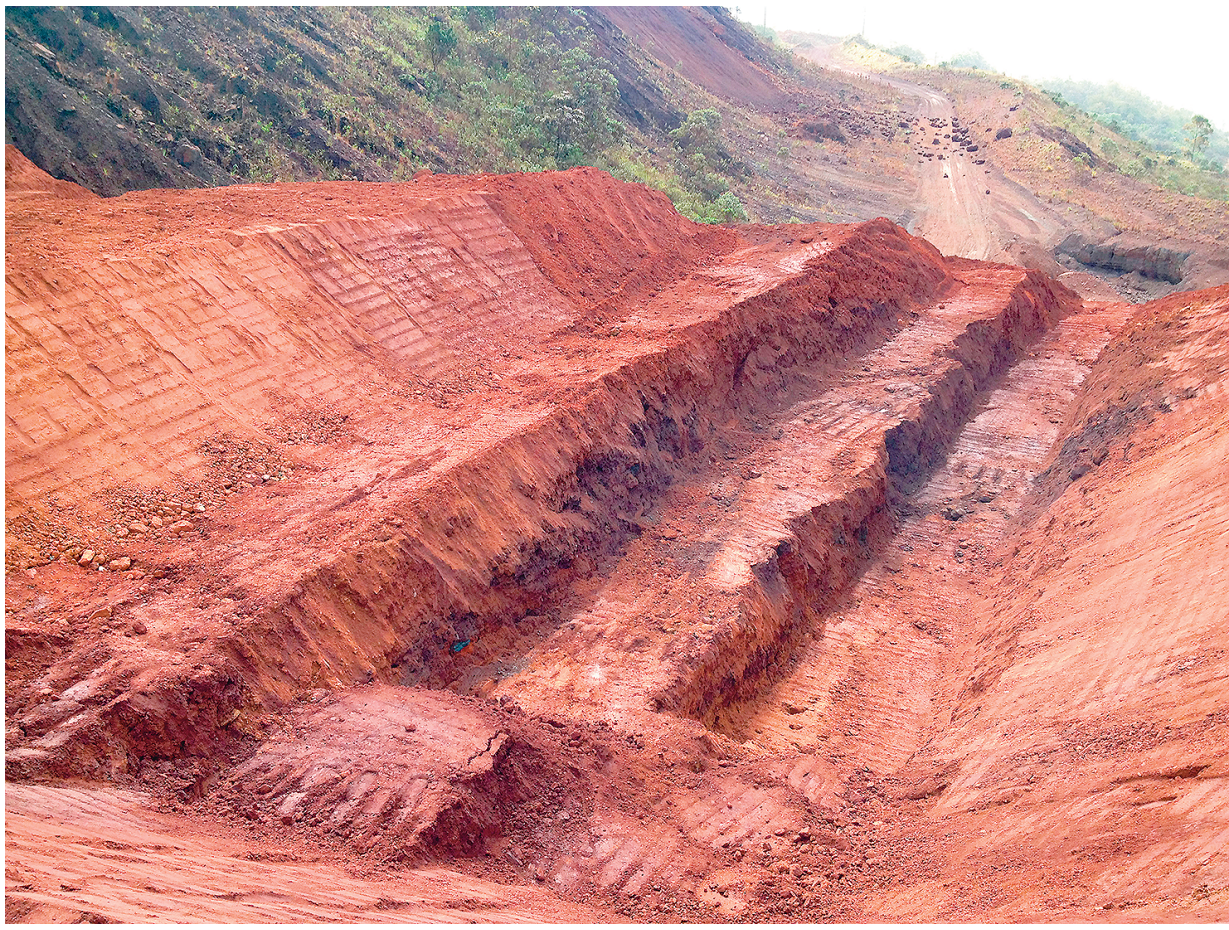

densities and 48 DCP tests. At least 2 DCP

tests were executed inside all density caves.

new layer, the process was repeated. At the end of the process, a layered 5-m bench was completed. In the layer method, as the dozer travels over the material to break the heaps, a certain compaction effort is transferred to the waste dump. Once the layered bench was finalized, the same procedures done at the bench waste dump were performed to obtain the density and resistance profiles. In the open pit, three berms were conformed to make room for 8 density and 48 DCP tests.

\subsection{Material geotechnical characterization}

Figure 4 presents the particle-size distribution curves corresponding to the waste material used to build all the test waste dumps. In case of the conveyor belt waste dump, only one test was carried out. A coarse texture

is apparent, due to the high percentage of gravel and sand. A percentage of fines above $12 \%$ (only one curve in fourteen has inferior percentage) is also observed. The specific gravity, which was also determined by the gas picnometer method, averages $4.48 \mathrm{~g} /$ $\mathrm{cm}^{3}$. When compared to the specific gravity of most types of soils, this is a very high value. This fact can be explained because a mineralized waste has significant iron content.
Figure 4

Grading curves for the waste material used to build the test waste dumps.

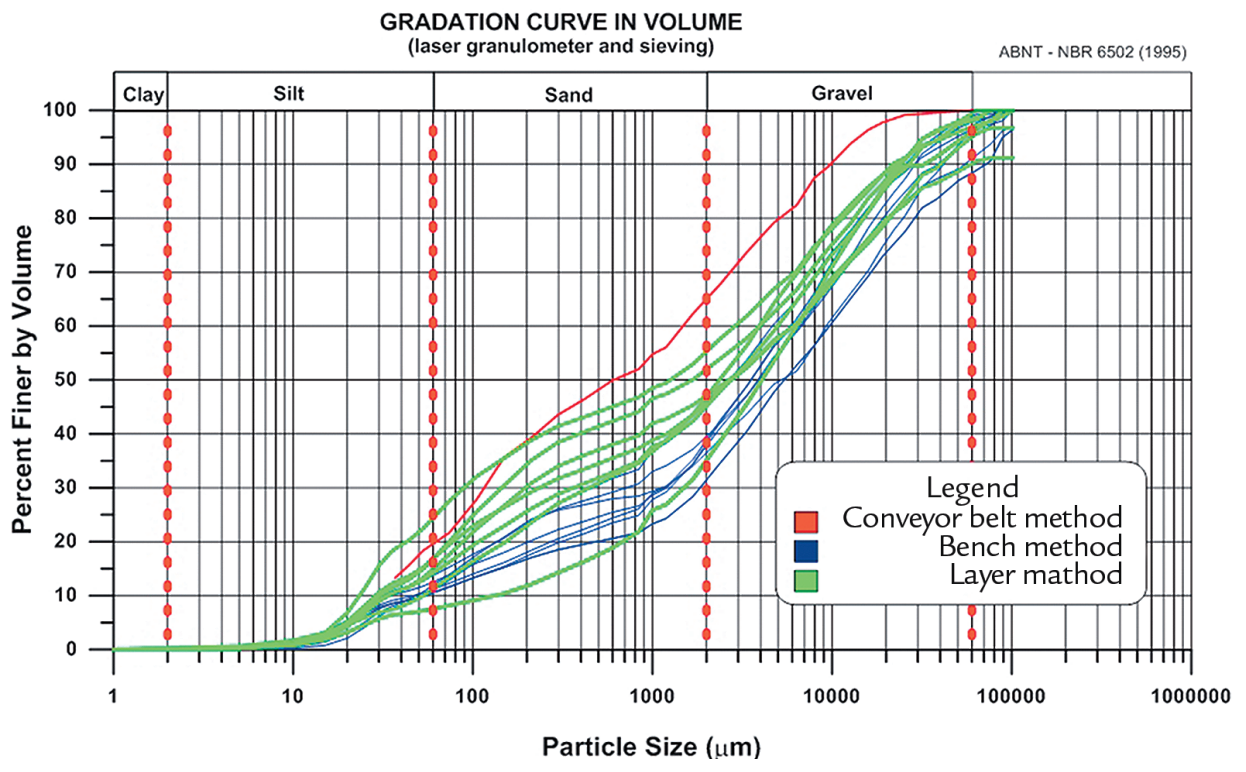

REM: R. Esc. Minas, Ouro Preto, 68(4), 479-484, oct. dec. | 2015 


\section{Results and discussions}

The in situ density and moisture con- tent profiles for the three test waste dumps
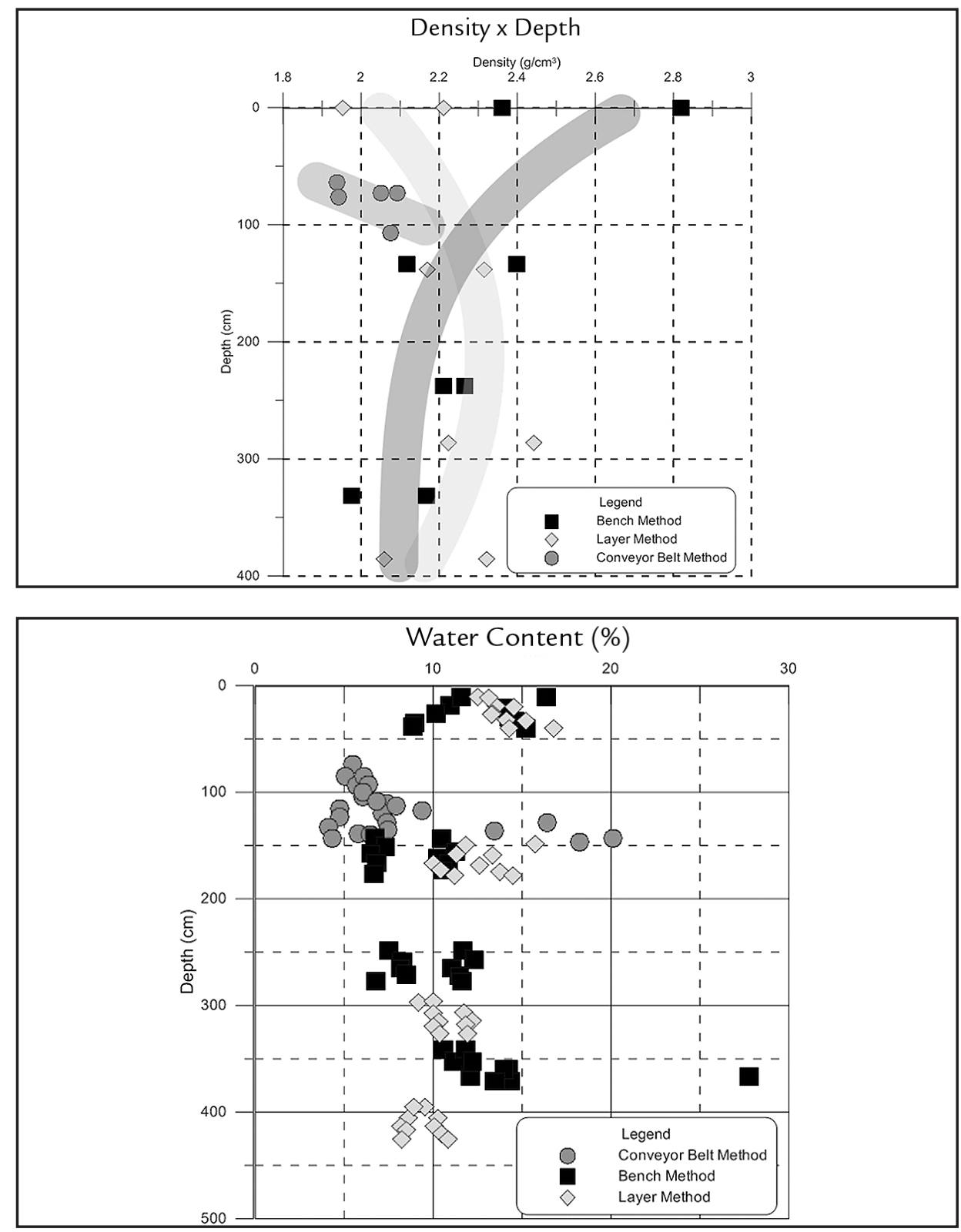

In the bench method, higher densities are found near the surface, probably in consequence of the hauling equipment traffic, which causes compaction. However, density decreases with depth, as expected, due to the attenuation of that compaction effort related to the equipment traffic. In the layer method, the density profile is almost uniform with depth. There is a slight increase in density every $1.5 \mathrm{~m}$ in depth, which corresponds to the layer thickness. Overall, the density averages of the layer and bench waste dumps are close, around $2.2 \mathrm{~g} / \mathrm{cm}^{3}$.

The average density corresponding to the conveyor belt waste dump is about $2.0 \mathrm{~g} / \mathrm{cm}^{3}$, which is $10 \%$ lower are shown in Figures 5 and 6, respectively.

Figure 5

In situ density results for all methods.

Figure 6

Moisture content for all methods.

$82 \%$ of the DCP tests in the conveyor belt dump, DCP averages 316, while in the remaining $18 \%$, DCP averages 831. This large discrepancy may be explained primarily by the particlesize distribution curve of the very loose waste material, a coarse well graduated soil with more than $20 \%$ of fines, and the random distribution of the gravel fraction in the dump mass.

Observing the DCP results for the two other waste dumps (Figure 8), the conclusion that both of them are consistent with the density profiles previously discussed could be drawn. Thus, for instance, bench dump DCP values increase with depth and are lower at the surface (meaning higher strength). 
Figure 7

Different DCP populations at the conveyor belt waste dump.
Figure 8

DCP results for all methods.

Finally, turning to an overall DCP data analysis, i.e., considering the three waste dumps, a considerable difference of values of the two traditional methods compared with the conveyor belt is observed in Figure 8 . The DCP test data regarding the two

\section{Conclusion}

The available waste disposal construction methods produce different waste dumps, as shown in this experimental research. Three waste dumps were built according to the bench, layer and conveyor belt and spreader methods. Resistance and density measurements were used to
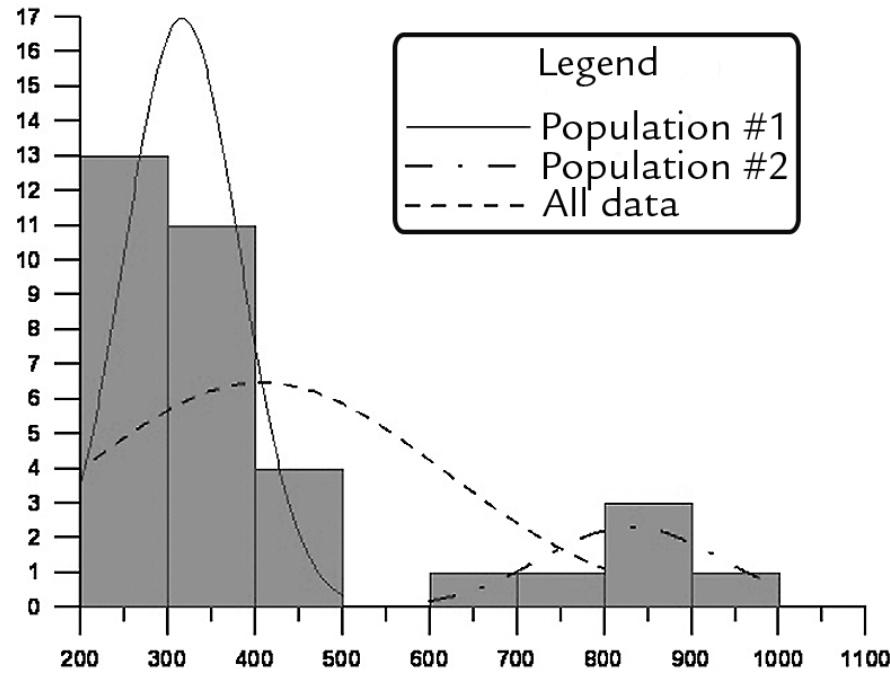

\section{Acknowledgments}

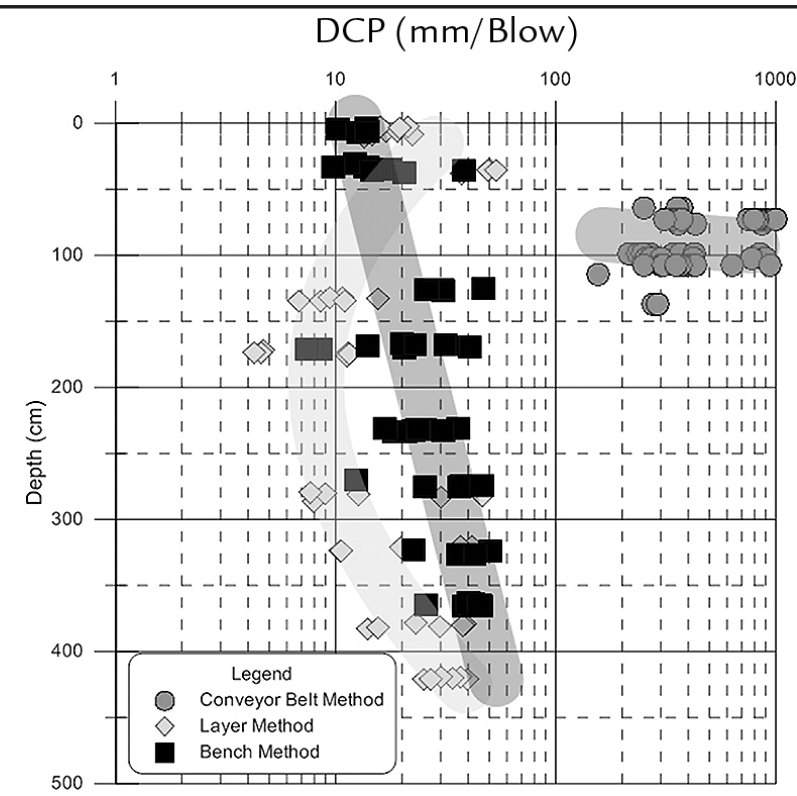

traditional methods are in the same range, around 30. Nevertheless, when compared to the conveyor belt values (around 300), the difference is very high, that is 10 times.

The overall results allow concluding that large differences in

compare those structures.

The most relevant finding was that the two traditional disposal methods present no significant differences regarding the structural strength. However, the same cannot be stated for the conveyor belt and spreader system. For the latter, densities could be $10 \%$ lower, and the performance for waste dumps built using the conveyor belt and spreader method are expected when compared with the usual waste disposal practice. This fact is really relevant and worth taking into account in the design of those dumps.

Authors thank UFOP and Samarco for funding this research. 


\section{Reference}

BUENO, B.,COSTA,Y. Buried pipelines, geotechnical aspects. (2 ${ }^{\text {a }}$ edition). In : Oficina de Textos. 2012. p. 26 - 41. (In Portuguese).

OLIVEIRA FILHO, W.L Triaxial test consideration on sands. Rio de Janeiro, COPPE - Federal University of Rio de Janeiro, 1987. (Msc. Dissertation - In Portuguese).

RESENDE, L.R.M., OLIVEIRA FILHO, W.L., NOGUEIRA, C.L. Use of the DCP test for compaction control of staged dikes in mining tailings dams. Rem: Rev. Esc. Minas [online]. 2013, v.66, n.4, p. 493-498.

SAMARCO MINERAÇÃO S.A. Natividadés waste pile project, 2009. (In Portuguese).

SAMARCO MINERAÇÃO S.A. Technical description for an exemplary fully mobile dumping system. THYSSENKRUPP Fördertechnik Latino America, 2010.

SCHRODER, D.L. The use of in-pit crushing and conveying methods to significantly reduce transportation costs by truck. In: COALTRANS ASIA CONFERENCE. Bali: 2003.

Received: 02 June 2014 - Accepted: 21 July 2015. 